\title{
METODE ANALYTIC HIERARCHY PROCESS DALAM MENENTUKAN PEMBOBOTAN FAKTOR-FAKTOR YANG MEMPENGARUHI KERENTANAN GEDUNG DI DKI JAKARTA TERHADAP ANCAMAN GEMPA
}

\author{
DETERMINING WEIGHTING FACTORS AFFECTING \\ VULNERABILITY BUILDING IN JAKARTA TOWARDS \\ EARTHQUAKE HAZARD USING ANALYTIC HIERARCHY \\ PROCESS METHOD
}

\author{
Raditya Panji Umbara ${ }^{1}$
}

\begin{abstract}
ABSTRAK: Daerah Khusus Ibukota (DKI) Jakarta berada pada zona ancaman gempa sedang, akan tetapi ada kemungkinan terjadi gempa skala besar. Gempa dapat memberikan ancaman terhadap gedung-gedung di DKI Jakarta. Di dalam tulisan ini akan dihitung nilai bobot dari faktor-faktor yang mempengaruhi kerentanan gedung di DKI Jakarta terhadap ancaman gempa menggunakan metode Analytical Hierarchy Process (AHP). Kriteria-kriteria yang dihitung dalam pembobotaan menggunakan AHP yaitu bentuk gedung, fungsi gedung, tahun desain, dan jumlah lantai. Dari hasil penghitungan pembobotan dapat digunakan untuk pembuatan peta kerentanan gedung di DKI Jakarta terhadap ancaman gempa.
\end{abstract}

Kata kunci: gempa, kerentanan, gedung, Analytical Hierarchy Process .

ABSTRACT: Jakarta is located in a moderate seismic threat zone, however there is a possibility of a large-scale earthquake to occur. Earthquakes can threaten buildings in Jakarta. This paper will calculate the weights of the factors affecting the vulnerability of buildings in Jakarta towards earthquakes hazard using Analytical Hierarchy Process (AHP) method. Criteria in weighting that are used in the calculations consist of building forms, building functions, building design, and the number of floors. The results of the weighting calculation can be used to develop the maps of building vulnerability in Jakarta toward earthquake hazard.

Keywords: earthquake, vulnerability, building, Analytical Hierarchy Process .

\section{PENDAHULUAN}

Menurut PetaAncaman Bahaya Gempa 2010 yang dikeluarkan oleh Kementerian Pekerjaan Umum, banyak kota besar yang berada pada zonasi ancaman gempa sedang

1. PTRRB - TPSA - BPPT, Laboratorium Geostech 820, Puspiptek, Serpong. email: raditya.panji86@gmail.com sampai gempa tinggi (Kementerian PU, 2010). Sebagai ibukota negara, Daerah Khusus Ibukota (DKI) Jakarta berada pada zona ancaman gempa sedang. Namun demikian ada kemungkinan terjadi gempa besar untuk skala 2.500 tahun (Pradono, 2013).

Gempa yang terjadi di DKI Jakarta pada tahun 2007 dan 2009 memiliki intensitas dengan skala MMI IV-V. Beberapa gedung bertingkat mengalami kerusakan berupa 
retak diagonal pada dinding, jatuhnya plafon, retaknya lantai dilatasi, dan kerusakan lain yang terlihat mata. Kerusakan ini tidak merusak struktur bangunan, yaitu kolom, balok, pelat lantai, dan dinding struktur (Pradono dan Triwinanto, 2010).

Mengingat kejadian tersebut dan dengan banyaknya gedung bertingkat di DKI Jakarta, perlu dikaji kerentanan gedung di DKI Jakarta terhadap ancaman gempa dengan metode kaji cepat. Kriteria dalam metode kaji cepat meliputi bentuk gedung, fungsi gedung, tahun desain dan jumlah lantai (Harris, 2013).

Tulisan ini bertujuan untuk mencari besarnya bobot dari faktor-faktor yang digunakan dalam analisis kerentanan gedung bertingkat di DKI Jakarta terhadap bencana gempa. Sehingga dapat diketahui seberapa besar pengaruh suatu faktor terhadap faktor lain. Hasil dari pembobotan ini dapat digunakan untuk membentuk peta kerentanan.

\section{METODOLOGI}

Penelitian dilakukan pada tahun 2014 dan 2015 terhadap 377 gedung yang ada di DKI Jakarta. Di dalam melakukan kajian kerentanan fisik gedung bertingkat di DKI Jakarta, maka ditentukan faktor-faktor yang mempengaruhi kerentanan struktur. Faktor tersebut adalah: bentuk gedung, fungsi gedung, tahun desain, dan jumlah lantai (Harris, 2013). Data tentang faktor-faktor yang telah terkumpul kemudian diolah menggunakan metode AHP yang pengolahannya menggunakan Microsoft Excel.

\subsection{Definisi Metode AHP}

Analitical Hierarchy Process (AHP) adalah suatu model pendukung keputusan yang dikembangkan oleh Thomas L. Saaty. Model AHP yaitu menguraikan masalah multifaktor atau multikriteria yang kompleks menjadi suatu hierarki yang lebih sistematis. Menurut Saaty (1993), hierarki tersebut direpresentasikan sebagai sebuah permasalahan yang kompleks dalam suatu struktur multilevel di mana level pertama adalah tujuan, yang diikuti level faktor, kriteria, subkriteria dan seterusnya ke bawah hingga level terakhir dari alternatif. Metode AHP bertujuan untuk mendapatkan prioritas keputusan yang lebih menyerupai proses pengambilan keputusan manusia (human decision process).

\subsection{Prinsip Dasar AHP}

\subsubsection{Dekomposisi}

Dekomposisi yaitu memecah permasalahan yang utuh menjadi unsurunsurnya. Struktur masalah yang kompleks dibagi menjadi bagian-bagian secara hierarki seperti Gambar 1 berikut.

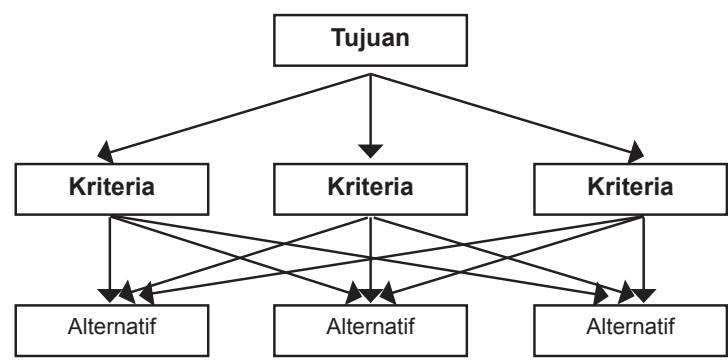

Gambar 1. Hierarki pada Metode AHP.

\subsubsection{Perbandingan Penilaian (ComparativeJudgments)}

Prinsip ini berarti membuat penilaian tentang kepentingan relatif dua elemen pada suatu tingkat tertentu dalam kaitannya ditingkat di atasnya. Penilaian ini merupakan inti dari AHP, karena akan berpengaruh terhadap prioritas elemen-elemen. Hasil perbandingan penilaian disajikan dalam bentuk matriks perbandingan berpasangan.

\subsubsection{Sintesa Prioritas (Synthesis of Priority)}

Dari matriks perbandingan berpasangan tersebut kemudian dicari eigenvector untuk mendapatkan bobot relatif bagi unsur-unsur pengambilan keputusan. 


\subsubsection{Konsistensi Logis (Logical Consistency)}

- $\quad$ Objek serupa dikelompokkan menurut keseragaman dan relevansinya.

- Tingkat hubungan antara objek-objek yang didasarkan pada suatu kriteria tertentu.

\subsection{Kelebihan Dan Kekurangan Metode AHP}

Seperti halnya model-model yang digunakan untuk analisis lainnya, metode AHP juga memiliki kelebihan dan kekurangan. Kelebihan metode AHP antara lain:

- Kesatuan (Unity), AHP dapat membuat suatu permasalahan yang luas dan tidak terstruktur menjadi masalah yang fleksibel dan mudah dipahami.

- Kompleksitas (Complexity), AHP dapat memecahkan suatu permasalahan yang kompleks melalui pendekatan sistem dan pengintegrasian secara deduktif.

- Saling ketergantungan (Inter Dependence), AHP dapat digunakan pada elemen-elemen sistem yang saling bebas dan tidak memerlukan hubungan linier.

- $\quad$ StrukturHierarki(HierarchyStructuring), AHP mewakili pemikiran alamiah yang cenderung mengelompokkan elemen sistem ke level-level yang berbeda dari masing-masing level berisi elemen yang serupa.

- Konsistensi (Consistency), AHP mempertimbangkan konsistensi logis dalam penilaian yang digunakan untuk menentukan prioritas.

Sedangkan kekurangan metode AHP yang paling utama adalah ketergantungan model AHP pada input utamanya. Diperlukan seorang ahli untuk menentukan input utamanya, sehingga masih melibatkan unsur subjektifitas. Fatalnya, model menjadi salah jika ahli tersebut memberikan penilaian yang keliru, sehingga untuk melakukan perbaikan keputusan harus dimulai lagi dari tahap awal.

\subsection{Tahapan Metode AHP}

Tahapan utama dalam metode AHP adalah mencari nilai bobot dan menguji konsistensi.

\subsection{Langkah-Langkah Dalam Mencari Nilai Bobot}

Langkah-langkah dalam mencari nilai bobot diuraikan pada bagian berikut ini:

1. Menentukan kriteria-kriteria yang akan menjadi persyaratan.

2. Membuat matriks perbandingan berpasangan.

Cara pengisian matriks berpasangan adalah sebagai berikut.

a. Misalkan matriks berpasangan adalah $A$ dengan sifat $A$ adalah matriks bujur sangkar dan ukurannya adalah sesuai dengan banyaknya kriteria.

$$
A_{n \times n}=\left[\begin{array}{cccc}
a_{11} & a_{12} & & a_{1 n} \\
a_{21} & a_{22} & \cdots & a_{2 n} \\
& \vdots & \ddots & \vdots \\
a_{n 1} & a_{n 2} & \cdots & a_{n n}
\end{array}\right]
$$

Jika banyaknya kriteria adalah 4 maka ukuran matriks berpasangan adalah $\mathrm{A}_{4 \times 4}$.

$$
A=\left[\begin{array}{llll}
a_{11} & a_{12} & a_{13} & a_{14} \\
a_{21} & a_{22} & a_{23} & a_{24} \\
a_{31} & a_{32} & a_{33} & a_{34} \\
a_{41} & a_{42} & a_{43} & a_{44}
\end{array}\right]
$$

b. $a_{[i, i]}=1$, di mana $\mathrm{i}=1,2,3, \ldots n$. Bilangan $n$ adalah banyaknya kriteria.

c. Elemen matriks segitiga atas sebagai input berdasarkan skala pada Tabel 1.

Elemen matriks segitiga atas:

$$
A_{n \times n}=\left[\begin{array}{cccc}
a_{11} & \boldsymbol{a}_{12} & \ldots & \boldsymbol{a}_{1 n} \\
a_{21} & a_{22} & \cdots & \boldsymbol{a}_{2 n} \\
& \vdots & \ddots & \vdots \\
a_{n 1} & a_{n 2} & \cdots & a_{n n}
\end{array}\right]
$$


Tabel 1. Skala Matriks Perbandingan Berpasangan (Saaty, 2008).

\begin{tabular}{|c|c|}
\hline $\begin{array}{l}\text { Intensitas } \\
\text { kepentingan }\end{array}$ & Keterangan \\
\hline \multirow[t]{2}{*}{1} & Kedua elemen sama pentingnya. \\
\hline & $\begin{array}{l}\text { Penjelasan: Dua elemen mempunyai } \\
\text { pengaruh yang sama besar terhadap } \\
\text { tujuan. }\end{array}$ \\
\hline \multirow[t]{2}{*}{3} & $\begin{array}{l}\text { Elemen yang satu sedikit lebih penting } \\
\text { daripada elemen yang lainnya. }\end{array}$ \\
\hline & $\begin{array}{l}\text { Penjelasan: Pengalaman dan } \\
\text { penilaian sedikit menyokong satu } \\
\text { elemen dibandingkan elemen lainnya. }\end{array}$ \\
\hline \multirow[t]{2}{*}{5} & $\begin{array}{l}\text { Elemen yang satu lebih penting } \\
\text { daripada elemen yang lainnya. }\end{array}$ \\
\hline & $\begin{array}{l}\text { Penjelasan: Pengalaman dan } \\
\text { penilaian sangat kuat menyokong satu } \\
\text { elemen dibandingkan elemen lainnya. }\end{array}$ \\
\hline \multirow[t]{2}{*}{7} & $\begin{array}{l}\text { Satu elemen jelas lebih mutlak penting } \\
\text { dari pada elemen lainnya. }\end{array}$ \\
\hline & $\begin{array}{l}\text { Penjelasan: Satu elemen yang kuat } \\
\text { disokong dan dominan terlihat dalam } \\
\text { praktik. }\end{array}$ \\
\hline \multirow[t]{2}{*}{9} & $\begin{array}{l}\text { Satu elemen mutlak penting daripada } \\
\text { elemen lainnya. }\end{array}$ \\
\hline & $\begin{array}{l}\text { Penjelasan: Bukti yang mendukung } \\
\text { elemen yang satu terhadap elemen } \\
\text { lain memiliki tingkat penegasan } \\
\text { tertinggi yang mungkin menguatkan. }\end{array}$ \\
\hline \multirow[t]{2}{*}{$2,4,6,8$} & $\begin{array}{l}\text { Nilai-nilai antara dua nilai pertimbangan } \\
\text { yang berdekatan. }\end{array}$ \\
\hline & $\begin{array}{l}\text { Penjelasan: Nilai ini diberikan jika ada } \\
\text { dua kompromi di antara dua pilihan. }\end{array}$ \\
\hline
\end{tabular}

d. Elemen matriks segitiga bawah berdasarkan elemen matriks segitiga atas, yaitu dengan menggunakan rumus berikut.

$a[j, i]=\frac{1}{a[i, j]}$, untuk $i \neq j$

Elemen matris segitiga bawah:

$$
A_{n \times n}=\left[\begin{array}{cccc}
a_{11} & a_{12} & & a_{1 n} \\
\boldsymbol{a}_{21} & a_{22} & \cdots & a_{2 n} \\
& \vdots & \ddots & \vdots \\
\boldsymbol{a}_{\boldsymbol{n} \mathbf{1}} & \boldsymbol{a}_{\boldsymbol{n} 2} & \cdots & a_{n n}
\end{array}\right]
$$

3. Mienormalisasikan matriks

Langkah-langkah

menormalisasi matriks: a. Menjumlahkan matriks kolom.

b. Menghitung nilai elemen dengan rumus masing-masing elemen kolom dibagi dengan jumlah matriks kolom.

Misalkan matriks normalisasi adalah $\mathrm{R}$, maka:

$$
\begin{aligned}
R_{11} & =\frac{a_{11}}{a_{11}+a_{21}+\cdots+a_{n 1}} \\
R_{12} & =\frac{a_{12}}{a_{12}+a_{22}+\cdots+a_{n 2}} \\
\cdots & =\frac{a_{11}}{a_{1 n}+a_{2 n}+\cdots+a_{n n}} \\
R_{1 n} & = \\
R_{n 1} & =\frac{a_{11}}{a_{11}+a_{21}+\cdots+a_{n 1}} \\
R_{n 2} & =\frac{a_{12}}{a_{12}+a_{22}+\cdots+a_{n 2}} \\
\cdots &
\end{aligned}
$$

Jadi, matriks normalisasi adalah

$$
{ }_{n \times n}=\left[\begin{array}{cccc}
r_{11} & \boldsymbol{r}_{12} & & \boldsymbol{r}_{1 \boldsymbol{n}} \\
r_{21} & r_{22} & \cdots & \boldsymbol{r}_{2 n} \\
& \vdots & \ddots & \vdots \\
r_{n 1} & r_{n 2} & \cdots & r_{n n}
\end{array}\right]
$$

4. Menghitung rata-rata tiap kriteria untuk mendapatkan vektor bobot (w) atau vektor eigen (eigenvector)

Rata-rata tiap kriteria diperoleh dari ratarata baris dari matriks ternormalisasi (hasil yang diperoleh pada langkah ke-3). Rata-rata diperoleh dari jumlah element tiap baris dibagi jumlah kriteria. Misalkan matriks normalisasi adalah $\mathrm{R}$,

$$
{ }_{n \times n}=\left[\begin{array}{cccc}
r_{11} & \boldsymbol{r}_{12} & \ldots & \boldsymbol{r}_{1 \boldsymbol{n}} \\
r_{21} & r_{22} & \cdots & \boldsymbol{r}_{2 n} \\
& \vdots & \ddots & \vdots \\
r_{n 1} & r_{n 2} & \cdots & r_{n n}
\end{array}\right]
$$

maka rata-rata tiap kriteria atau vektor bobot (w) adalah: 


$$
w=\left[\begin{array}{c}
\frac{r_{11}+r_{12}+\cdots+r_{1 n}}{n} \\
\frac{r_{21}+r_{22}+\cdots+r_{2 n}}{n} \\
\vdots \\
\frac{r_{n 1}+r_{n 2}+\cdots+r_{n n}}{n}
\end{array}\right]
$$

Nilai rata-rata tersebut merupakan nilai bobot yang dicari. Tetapi perlu langkah selanjutnya, yaitu dengan menguji konsistensi dari input utama yang diperoleh dari para ahli, sehingga kriteria-kriteria tersebut konsisten dan memenuhi standar.

\subsection{Langkah-Langkah Untuk Menguji Konsistensi}

1. Mencari rata-rata konsistensi $(\gamma)$ atau nilai eigen (eigenvalue).

Suatu matriks bujur sangkar A dengan orde $\mathrm{n} \times \mathrm{n}$ dan sebuah vektor $\mathrm{w}$ dalam ruang $R^{n}$ yang memenuhi persamaan: $A w=\lambda w$

$\gamma$ adalah suatu skalar dan $w$ adalah vektor yang tidak nol. Skalar $\gamma$ dinamakan nilai eigen dari matriks $A$. Nilai eigen adalah nilai karakteristik dari suatu matriks bujur sangkar. Vektor w adalah suatu vektor yang tidak nol yang memenuhi persamaan tersebut untuk nilai eigen yang sesuai dan disebut dengan vektor eigen. Jadi vektor w mempunyai nilai tertentu untuk nilai eigen tertentu.

Langkah-langkah mencari rata-rata konsistensi:

a. Mengalikan matriks berpasangan (A) dengan vektor bobot (w).

b. Mencari vektor konsistensi dengan cara membagi tiap-tiap elemen hasil Aw dengan elemen-elemen pada vektor bobot (w).

c. Nilai rata-rata konsistensi merupakan rata-rata setiap elemen pada vektor konsistensi.

2. Menghitung indeks konsistensi atau concistency index $(\mathrm{Cl})$

Indeks Konsistensi dari matriks berordo $\mathrm{n}$ adalah:

$$
C I=\frac{\lambda_{\text {maks }}-n}{n-1}
$$

Keterangan:

$\gamma_{\text {maks }}=$ Nilai eigen terbesar dari matriks berordo $\mathrm{n}$

$\mathrm{n}=$ Orde matriks

3. Menghitung rasio konsistensi atau concistency ratio(CR)

Batas ketidakkonsistensinan yang telah ditetapkan dengan menggunakan rasio konsistensi (CR), yaitu:

$\mathrm{CR}=\mathrm{Cl} / \mathrm{RI}$

Keterangan:

$\mathrm{Cl}=$ indeks konsistensi

$\mathrm{RI}=$ random index atau indeks inkonsistensi acak

Nilai RI berdasarkan banyaknya kriteria ditunjukkan oleh Tabel 2 berikut.

Tabel 2. Indeks Inkonsistensi Acak untuk $n=1,2,3, \ldots, 10$.

\begin{tabular}{|c|c|}
\hline n (Banyaknya Kriteria) & RI (Random Indeks) \\
\hline 1 & 0 \\
\hline 2 & 0 \\
\hline 3 & 0,58 \\
\hline 4 & 0,9 \\
\hline 5 & 1,12 \\
\hline 6 & 1,24 \\
\hline 7 & 1,32 \\
\hline 8 & 1,41 \\
\hline 9 & 1,45 \\
\hline 10 & 1,49 \\
\hline
\end{tabular}

Tingkat konsistensi yang masih bisa diterima adalah $0<C R<0,1$ (Saaty, 1993). Jika CR > 1 maka harus direvisi input utamanya dan dilakukan dari tahap awal. Jika nilai adalah $0<\mathrm{CR}<0,1$, maka hasilnya konsisten, sehingga vektor bobot (w) yang dihasilkan dapat digunakan untuk analisis lanjutan.

\section{Hasil Dan Pembahasan}

Pada bagian ini akan dibahas mengenai inputan utama ahli, proses 
perhitungan, dan keluaran yang dihasilkan dari penghitungan pembobotan faktor-faktor yang mempengaruhi kerentanan gedung bertingkat di DKI Jakarta terhadap bencana gempa.

\subsection{Mencari Vektor Bobot Menggunakan Metode AHP}

Pembobotan berdasarankan hasil penghitungan dengan metode AHP. Tiaptiap kriteria dibuat matriks berpasangan berdasarkan Tabel 1.

1. Menentukan kriteria-kriteria yang akan menjadi persyaratan.

Kriteria-kriteria yang akan dicari bobotnya antara lain bentuk gedung, jumlah lantai gedung, tahun desain, dan fungsi gedung. Pengaruh faktor tersebut dalam kerentanan diterangkan sebagai berikut (Harris, 2013).

- Faktor bentuk gedung.

Berdasarkan FEMA 154, bangunan yang teratur bentuknya lebih aman terhadap bahaya gempa. FEMA membagi ketidakteraturan dalam ketidakteraturan vertikal dan ketidakteraturan denah (Gambar 2 dan Gambar 3).

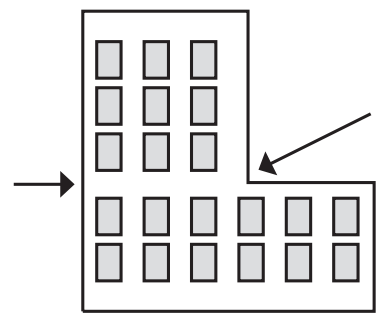

Perubahan Mendadak
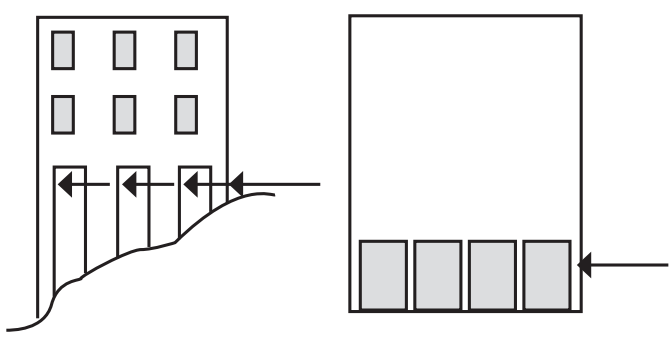

Gambar 2. Ketidakteraturan Vertikal (FEMA, 2002).
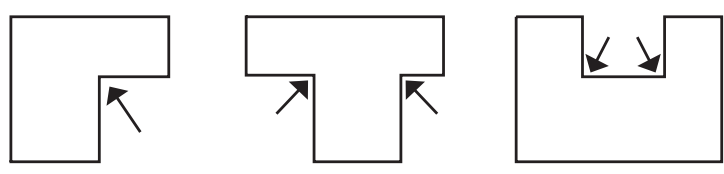

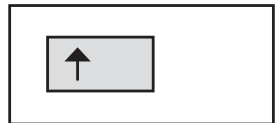

Bentuk O

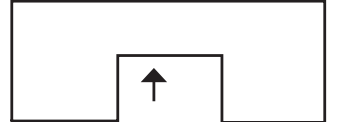

Penghubung Lemah antar Dua Bangunan
Gambar 3. Ketidakteraturan Denah (FEMA, 2002).

- Faktor fungsi gedung.

Berdasarkan

Peraturan

Pembebanan Indonesia, maka fungsi gedung mempengaruhi berat desain lantai gedung.

- Faktor tahun desain gedung.

Peraturan desain bangunan tahan gempa berubah terus seiring dengan pengetahuan mengenai kegempaan di Indonesia. Standar desain bangunan tahan gempa di Indonesia berubah pada tahun 1987, tahun 2002, dan tahun 2010. Ada peningkatan spektrum desain gempa dari tahun 1987 ke tahun 2002 untuk zona kegempaan di daerah Jakarta.

- Faktor jumlah lantai gedung. Untuk bangunan tinggi, karena waktu getar alami bangunan mengalami peningkatan, maka koefisien gaya gempa mengecil sehingga desain kolom untuk gaya gempa dan untuk gaya gravitasi menghasilkan kolom yang hampir sama dimensinya.

\section{Menentukan matriks perbandingan berpasangan.}

Kemudian dilakukan skala perbandingan berpasangan untuk tiaptiap kriteria tersebut. Diperoleh matriks perbandingan berpasangan seperti pada Tabel 3 berikut. 
Tabel 3. Matriks Perbandingan Berpasangan.

\begin{tabular}{|l|c|c|c|c|}
\hline Kriteria & Bentuk & Lantai & Fungsi & Tahun \\
\hline Bentuk & 1 & 3 & 7 & 5 \\
\hline Lantai & $1 / 3$ & 1 & 5 & 3 \\
\hline Fungsi & $1 / 7$ & $1 / 5$ & 1 & $1 / 3$ \\
\hline Tahun & $1 / 5$ & $1 / 3$ & 3 & 1 \\
\hline
\end{tabular}

Penjelasan matriks berpasangan adalah sebagai berikut.

- Bentuk gedung sedikit lebih penting dari jumlah lantai.

- Bentuk gedung satu elemen jelas lebih mutlak penting dari fungsi bangunan.

- Bentuk gedung lebih penting dari tahun pendirian bangunan.

- Jumlah lantai lebih penting dari fungsi bangunan.

- Jumlah lantai sedikit lebih penting dari tahun pendirian bangunan.

- Tahun pendirian bangunan sedikit lebih penting dari fungsi bangunan.

\section{Menormalisasikan Matriks.}

Normalisasi matriks dengan cara membagi elemen-elemen pada matriks berpasangan dengan jumlah nilai elemen tiap kolom.

Tabel 4. Jumlah Matriks Kolom.

\begin{tabular}{|l|c|c|c|c|}
\hline Kriteria & Bentuk & Lantai & Fungsi & Tahun \\
\hline Bentuk & 1 & 3 & 7 & 5 \\
\hline Lantai & 0,333 & 1 & 5 & 3 \\
\hline Fungsi & 0,143 & 0,2 & 1 & 0,333 \\
\hline Tahun & 0,2 & 0,333 & 3 & 1 \\
\hline Jumlah & $\mathbf{1 , 6 7 6 2}$ & $\mathbf{4 , 5 3 3 3}$ & $\mathbf{1 6}$ & $\mathbf{9 , 3 3 3 3}$ \\
\hline
\end{tabular}

Tabel 5. Matriks Normalisasi.

\begin{tabular}{|l|c|c|c|c|}
\hline Kriteria & Bentuk & Lantai & Fungsi & Tahun \\
\hline Bentuk & 0,5966 & 0,6618 & 0,4375 & 0,5357 \\
\hline Lantai & 0,1989 & 0,2206 & 0,3125 & 0,3214 \\
\hline Fungsi & 0,0852 & 0,0441 & 0,0625 & 0,0357 \\
\hline Tahun & 0,1193 & 0,0735 & 0,1875 & 0,1071 \\
\hline Jumlah & $\mathbf{1}$ & $\mathbf{1}$ & $\mathbf{1}$ & $\mathbf{1}$ \\
\hline
\end{tabular}

Pada matriks normalisasi (Tabel 5) jumlah setiap matriks kolom adalah 1.

4. Menghitung rata-rata tiap kriteria untuk mendapatkan vektor bobot (w) atau vektor eigen (eigenvector).

Setelah mendapatkan matriks normalisasi, kemudian dicari rata-rata tiap kriteria, yaitu dengan cara mencari rata-rata tiap baris. Rata-rata tiap kriteria tersebutlah yang dinamakan vektor bobot (Tabel 6).

Tabel 6. Vektor Bobot.

\begin{tabular}{|l|c|}
\hline Kriteria & Rata-rata \\
\hline Bentuk & 0,5579 \\
\hline Lantai & 0,2633 \\
\hline Fungsi & 0,0569 \\
\hline Tahun & 0,1219 \\
\hline
\end{tabular}

\subsection{Menguji Konsistensi}

Setelah mendapatkan vektor bobot, kemudian akan dicari konsistensi dari vektor bobot tersebut. Langkah-langkahnya adalah sebagai berikut.

1. Mencari rata-rata konsistensi $(\gamma)$ atau nilai eigen (eigenvalue)

a. Mengalikan matriks berpasangan dengan vektor bobot.

Tabel 7. Vektor Aw.

\begin{tabular}{|l|l|c|}
\hline \multirow{4}{*}{ Aw } & Bentuk & 2,3555 \\
\cline { 2 - 3 } & Lantai & 1,0994 \\
\cline { 2 - 3 } & Fungsi & 0,2299 \\
\cline { 2 - 3 } & Tahun & 0,4919 \\
\hline
\end{tabular}

b. Mencari Vektor Konsistensi dan Rata-Rata Konsistensi $(\lambda)$.

Tabel 8. Vektor Konsistensi.

\begin{tabular}{|l|l|c|c|}
\hline \multirow{4}{*}{ Aw } & Bentuk & $2,3555: 0,5579=$ & 4,2222 \\
\cline { 2 - 4 } & Lantai & $1,0994: 0,2633=$ & 4,1747 \\
\cline { 2 - 4 } & Fungsi & $0,2299: 0,0569=$ & 4,0408 \\
\cline { 2 - 4 } & Tahun & $0,4919: 0,1219=$ & 4,0362 \\
\hline \multirow{2}{*}{} & \multicolumn{2}{|l|}{ Jumlah } & 16,4739 \\
\hline & \multicolumn{2}{|l|}{ Rata-rata konsistensi $(\lambda)$} & 4,1185 \\
\hline
\end{tabular}


2. Menghitung indeks konsistensi atau concistency index $(\mathrm{Cl})$

$$
C I=\frac{\lambda-n}{n-1}=\frac{4,1185-4}{4-1}=0,0296
$$

$\mathrm{n}=$ jumlah kriteria. Pada kasus ini ada 4 kriteria.

3. Menghitung indeks konsistensi atau concistency index $(\mathrm{Cl})$

$$
C R=\frac{C I}{R I}=\frac{0,0296}{0,90}=0,0329
$$

Untuk jumlah kriteria 4, maka nilai Ri adalah 0,9 .

Nilai akhir CR adalah 0,0329 yang berarti $0<C R<0,1$, sehingga model yang dihasilkan konsisten. Dengan demikian, nilai bobot berdasarkan kriteria-kriteria yang ditentukan adalah seperti pada Tabel 9 dan Gambar 4 berikut.

Tabel 9. Bobot Tiap Kriteria dari FaktorFaktor yang Mempengaruhi Kerentanan Gedung di DKI Jakarta terhadap Bencana Gempa.

\begin{tabular}{|l|c|}
\hline Kriteria & Rata-rata \\
\hline Bentuk & 0,5579 \\
\hline Lantai & 0,2633 \\
\hline Fungsi & 0,0569 \\
\hline Tahun & 0,1219 \\
\hline
\end{tabular}

$12,19 \%$

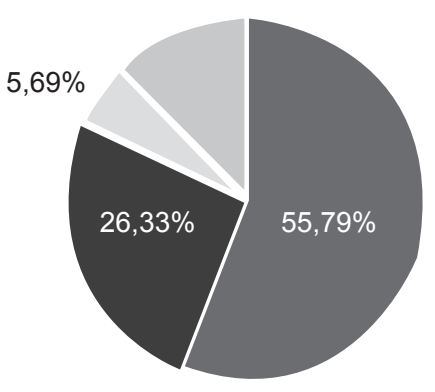

Bentuk

Lantai

Fungsi

Tahun

Gambar 4. Bobot Tiap Kriteria dari FaktorFaktor yang Mempengaruhi Kerentanan Gedung di DKI Jakarta terhadap Bencana Gempa (dalam persentase).

\section{KESIMPULAN}

Berdasarkan hasil penghitungan nilai rasio konsistensi (CR) adalah 0,0329 yang berarti $0<\mathrm{CR}<0,1$ (sesuai standar), sehingga nilai bobot untuk keempat kriteria dari ahli dapat digunakan untuk menentukan tingkat kerentanan gedung yang berlokasi di DKI Jakarta terhadap gempa.

Bentuk gedung sangat mempengaruhi nilai kerentanan dengan persentase terbesar yaitu $55,79 \%$ dan fungsi gedung memiliki bobot persentase terkecil 5,69\%. Artinya bentuk gedung hampir 10 kali lebih berpengaruh dibandingkan fungsi gedung. Sehingga sangat dianjurkan dalam membuat gedung perlu memperhatikan bentuk gedung. Setelah bentuk gedung, faktor yang berpengaruh adalah jumlah lantai $(26,33 \%)$ disusul oleh tahun pembuatan gedung $(12,19 \%)$. Semakin banyak jumlah lantai, gedung tersebut semakin rentan karena karena waktu getar alami bangunan mengalami peningkatan. Tahun pembuatan berkaitan dengan standar desain bangunan tahan gempa di Indonesia.

Pembobotan menggunakan AHP masih bergantung pada subjektivitas para ahli sebagai input awal. Jika input awal ahli keliru maka hasil model menjadi keliru, sehingga untuk melakukan perbaikan keputusan harus dimulai lagi dari tahap awal.

\section{DAFTAR PUSTAKA}

FEMA, 2002, Rapid Visual Screening of Buildings for Potential Seismic Hazards, FEMA 154, National Earthquake Hazards Reduction Program, Edition 2 / March 2002.

Pradono, M. H. dan P. Triwinanto, 2010, Evaluasi Kekuatan Struktur Gedung BPPT Pasca Gempa Tasikmalaya 2 September 2009, Jurnal Sains dan Teknologi Mitigasi Bencana, Vol. 5, No. 1, Hal. 16-30.

Pradono, M. H. 2013, Intensitas Gempabumi DKI Jakarta berdasarkan Peta Hazard Gempa Indonesia 2010. Dalam: Jurnal Sains dan Teknologi Mitigasi Bencana. Vol. 8. No. 1. Juni. Hal.: 1-8. 
Hartati, Ridha Vera, 2009, Pendekatan Model Fuzzy Goal Programming dalam Penetapan Pembobotan Priorotas dari Metode Analytical Hierarchy Process (AHP), Skripsi, Fakultas Matematika dan IImu Pengetahuan Alam, Universitas Sumatera Utara.

Saaty, T. Lorie, 1993, Pengambilan Keputusan Bagi Para Pemimpin, Proses Hirarki Analitik untuk Pengambilan Keputusan dalam Situasi yang Kompleks, Pustaka Binama Pressindo.

Saaty, T. Lorie, 2008, Decision Making with The Analytic Hierarchy Process. Int. J. Services Sciences, Vol. 1, No. 1. DOI: 10.1504/ IJSSCI.2008.017590.
http://en.wikipedia.org/wiki/Analytic_hierarchy_ process. Diakses pada 29 Oktober 2014.

http://en.wikipedia.org/wiki/Eigenvalues_and_ eigenvectors. Diakses pada 29 Oktober 2014.

http://www.sistemphp.com/21-kelebihan-dan4-kelemahan-metode-ahp-dibandingmetode-lain/. Diakses pada 29 Oktober 2014. 